\title{
REFERENCES
}

Green D. P. (1988) Operative Hand Surgery Volume 2. pp. 1043 Churchill Livingstone, Edinburgh. Jenkins N. H. \& Mackie I. G. (1988) Late rupture of Extensor Pollicis Longus Tendon: The case against attrition. Journal of Hand Surgery 13-B, 4, 448-9.

\section{Swallowed foreign body}

Sir,

This X-ray (Fig 1) taken in our department's Resuscitation room, was of a 5 yearold girl who had swallowed a five pence coin. This was subsequently removed on emergency oesophagoscopy from the upper 3rd of the oesophagus. While it is well known in specialist circles (E.N.T.) that it is possible to distinguish from a plain

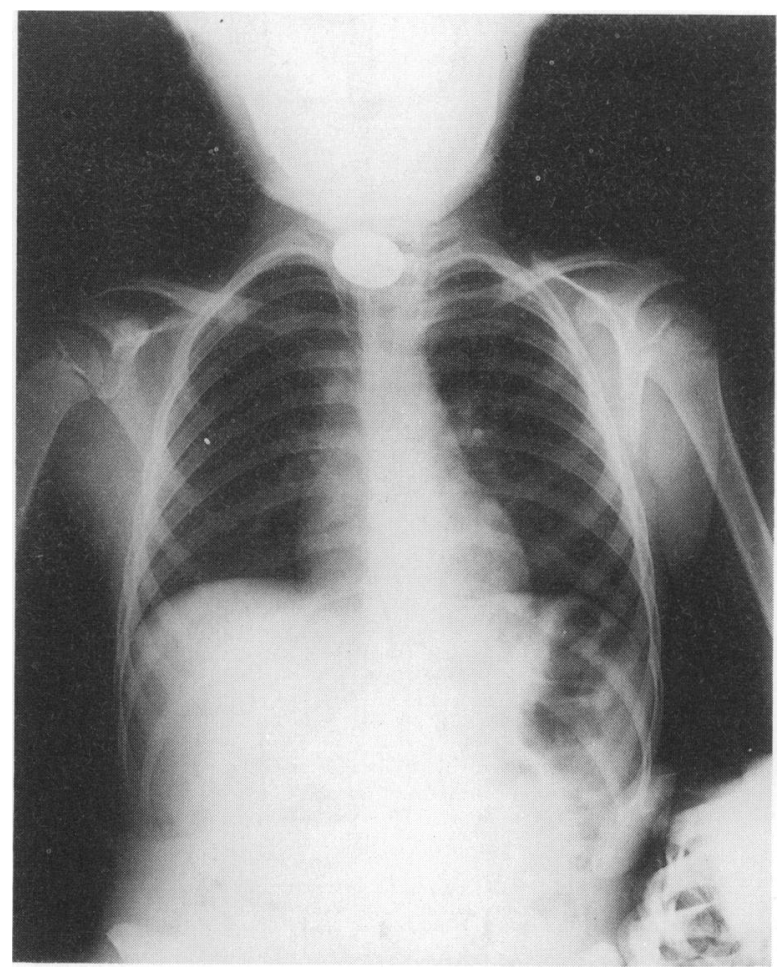

Fig. 1 Radiograph of child with coin visible in upper oesophagus.

radiograph of the neck whether the coin is in the oesophagus or the larynx, it was felt this knowledge is not widespread among junior Accident and Emergency staff. 
A coin stuck in the upper oesophagus appears face on, as in this film, whereas a coin stuck in the larynx, with its obvious more serious consequences, appears end on.

B. SEN, A. K. MAITRA \& M. WEATHERHEAD

Accident and Emergency Department

Royal Victoria Infirmary

Newcastle upon Tyne 